\title{
Early Pregnancy Symptom
}

National Cancer Institute

\section{Source}

National Cancer Institute. Early Pregnancy Symptom. NCI Thesaurus. Code C92771.

A characteristic complaint in a fertile woman that is indicative of a pregnancy. 